\title{
Integrating Financial Perspectives in Examining the Factors and Context of E-Commerce Utilization among Selected Canadian Firms
}

\author{
Ahmed Alojairi', Abdullah Almansour' ${ }^{2}$, Abdullah Basiouni ${ }^{3}$, Kang Mun Arturo Tan ${ }^{3}$, \\ Hafizi Muhamad Ali ${ }^{3, *}$ and Walid Bahamdan 4 \\ 1Department of Accounting and Management Information Systems, King Fahd University of Petroleum and \\ Minerals (KFUPM), Dhahran, Kingdom of Saudi Arabia; alojairi@kfupm.edu.sa \\ 2Department of Economics and Finance, King Fahad University of Petroleum and Minerals (KFUPM), Dhahran, \\ Kingdom of Saudi Arabia; amansour@kfupm.edu.sa \\ ${ }^{3}$ Department of Management Sciences, Yanbu University College, Yanbu Al Sinaiyah, Kingdom of Saudi Arabia; \\ basiounia@rcyci.edu.sa, tank@rcyci.edu.sa, alih@rcyci.edu.sa \\ 4Sara Holding, Riyadh, Kingdom of Saudi Arabia; wbahamdan@bahamdan.com
}

\begin{abstract}
Objectives: The study aims to examine the factors and context that encourage the adoption of e-commerce among selected Canadian companies. Methods: The study employed Benaroch use of real-option theory in assessing risk factors from 811 Canadian companies. Furthermore, the NEBIC model was used to analyse firms' capacity in managing e-commerce. Data were analysed using maximum likelihood estimation, correlation matrix, and $t$-test of means equality. Findings: The study arrived at the following conclusion on the basis of the results obtained: technology-competent employees, competitive industry, and high variability of consumer sales positively correlate with the decision to use e-commerce. Applications: The study also found the agility of the firm to work on e-commerce positively correlates with e-commerce usage. Agility is attained by intensive e-commerce technology in-house training, encouraging its customers to use its e-commerce facility, and promoting e-commerce among other members of the industry.
\end{abstract}

Keywords: E-commerce, Information Technology Investment, Real Option, Selling Online

\section{Introduction}

E-commerce has been considered a key strategy for many companies. Since the advent of the Internet, many companies have tried to use this channel to boost sales. There are a few success stories, but due to the low entry cost, even though many have tried using it to boost sales, their sales volume through the Internet has not been substantial. $\underline{1}^{-\underline{3}}$

In this study, the real-option approach, together with other statistical techniques, was used to explain why a business would consider e-commerce. This study contributes to the literature by using real-option theory as a method of dealing with uncertainties associated with investments.

Further, using appropriate statistical techniques this study also dissected the risks involved in e-commerce adoption. Due to their quantitative orientation, the techniques utilized in the present study pointed to the direction in which a certain variable favoured the decision to adopt e-commerce.

Moreover, this study starts with presenting the theoretical background of the real-option theory, followed by 4 a discussion on the features of Information Technology Risk Management. This discussion proceeds to present three hypotheses. These hypotheses were

${ }^{*}$ Author for correspondence 
then analysed based on the data presented, one from innovation in e-business models,,$\frac{5,6}{6}$ and the other from Statistics Canada. Subsequently, this article presents an interpretation and discussion of the study findings.

\section{Theoretical Background}

The literature shows that there are two major reasons for adopting e-commerce: in-house organizational competency, and business environment and product characteristics.

E-commerce adoption refers to the conduct of business transactions, maintenance of business relationships, and sharing of information with the public. This managerial decision would mean time and space barriers are removed, bringing in substantial benefit to the business. Not only does it extend the conduct of business operations to a 24 $\mathrm{X} 7$ schedule but also projects its availability to the global audience $24 \mathrm{X} 7$ throughout the year..,$\underline{8}$

Different works have considered various factors affecting the consideration of e-commerce. These factors are as follows: features of the enterprise's product,,$\underline{9,10}$ shortcoming of the enterprise's e-commerce systems and facilities $\frac{11}{1}$; current business model's inertia $\frac{12}{12}$; costs related to online sales $\underline{13}, \underline{14}$; and risks and threats. $\underline{12,15}$

On the other hand, there are various papers that discussed factors internal to the firms. These factors include insufficient support of management $\underline{16,17}$ and the general lack of or inadequate know-how of staff about information technology. 17

The TOE (Technology, Organization, and Environment) Framework suggests that the development of technology, organizational conditions, and industry environment $\frac{18, \underline{19}}{}$ drives the adoption of e-commerce.

The decision to go on-line involves a lot of changes within the firm and some investments in real assets. To assess this type of a decision, we adopted in this study the real-option framework. $\operatorname{In}^{20}$ it was noted that "real-options investments are characterized by sequential, irreversible investments made under conditions of uncertainty." $\underline{20}$

Various papers have applied the real-option framework in different types of financial capital decisions in various industrial situations. $\underline{21}-\underline{26}$ The framework offers analytical tools to value alternatives that arise from considering various investment decisions, such as a decision to initiate a project now or later; decision to expand the business operation, or decision to abandon the whole or part of business operations. In addition to these is the option to learn. $\underline{27}$ The "learning" option is synonymous with the option to defer or wait, except that in this case, the firm emerges wiser and ready to tackle the issue from a different angle.

The key assumption of real-option framework is the irreversibility of investment; that is, once the firm has invested a specific amount, the investors never recover the original amount in whole. Expanding on this idea, as the firm adopts e-commerce, the organization changes its operational behavior. As new employees are hired to help in this new mode of doing business, the culture of the organization shifts as well. Besides, new technology, in the form of computers and software, is brought in. A decision, therefore, to revert, such as to let go of the hired employees or sell all the technology acquired as part of this project, will not allow the firm to recover its initial investment. In other words, the adoption of e-commerce can be treated as an irreversible investment. $\underline{28}$

In $\underline{29}$ it was noted that under a higher-level irreversibility of assets, there is a negative relationship between uncertainty and investments. Essentially, the presence of irreversibility and uncertainty tends to dampen the value of assets. Such irreversibility and uncertainty are brought about by the absence of an appropriate second-hand market. Part of the elements of the real-option framework includes the engagement of flexibility-attaining activities to maintain or enhance the recovery sale value.

In discussing this investment decision, we invoke $\underline{4}^{\text {'s }} \mathrm{s}$ use of real-option theory on information technology investments. $\mathrm{In}^{4}$ it was stipulated that to consider the investment in information technology, the firm has to consider three types of risks: firm-specific risks (threats related to the firm), competition risks (threats coming from rival firms), and market risks (threats related to consumer demand). These firm-specific risks refer to the chances that the in-house competence to manage e-commerce related technology would not be developed adequately. Moreover, the competition risks refer to the firm's inability to protect its market. This situation allows the competition to snatch the market opportunity. Finally, the market risks refer to the chances that the customer's demands for services or product generated from the target investment would diminish. $\underline{25,26, \underline{30}}$

\section{Research Model}

Pursuing this point, $\underline{4}$ the following equation is suggested as a basis in considering the decision to invest. 


$$
\Pi^{\circ}=\mathrm{E}(\mathrm{NPVonline})-\mathrm{E}(\mathrm{NPVoffline})-\mathrm{I}>0
$$

The E(NPVonline) refers to the expected value of the business if a firm adopts e-commerce, while the $\mathrm{E}$ (NPVoffline) refers to the expected value of the business if the firm ignores e-commerce. Therefore, the difference in the online-offline equation is what makes it attractive to most decision-makers.

However, central to the issue of real-option theory is the concept of risks, and how we concretize this risk variable. In focusing the analysis on risk factors, the firm might be able to seize upside opportunities and reduce

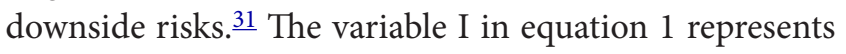
uncertainties inherent in many investment decisions.

The value of variable I refer to the idea of waiting for some information or the cost associated with "bad events." Alternatively, it is the value of the risk of failures. The variable I can be a function of three variables: failed internal capability, situated with a strong competitor, and faded market demand.

In this study, we present the following discussion that would lead to the following hypotheses.

We have observed that firms with higher internal capabilities do not wait for additional information. In other domains, like that of, $\underline{32}$ it has been noted that farmers having better information about farming do not wait; rather, they adopt new farming techniques. Hence, we assert the following hypothesis:

H1: Firms whose staff can manage technology are more likely to employ e-commerce.

Moreover, we noted that firms doing business in a tighter competitive environment tend to adopt newer technology. In $\underline{33}$ it was noted that for a firm surrounded by a large set of players, the variability in the competition has little impact on the option to wait. Furthermore, $, \underline{3}, \underline{6}$ showed that firms in an industry that conducts business over the Internet have a higher tendency to employ e-commerce. Hence, we present the following hypothesis:

H2: Firms operating in an area with more competitive companies are more likely to adopt e-commerce.

Finally, we note from the literature that firms operating in high-demand and uncertain environment tend to delay the adoption of newer technologies. Intuitively, this is a "play-safe" attitude of many business owners, who wait for the storm to subside before taking a decision to invest further. Hence, we propose the following hypothesis:

H3: Firms experiencing a high variability in their demand are less likely to adopt e-commerce.
These three hypotheses assert that the value of variable I in equation 1 decrease as internal capabilities increase, just as the value of variable I decreases as the size of competition increases. Similarly, the value of variable I increases as the uncertainties of demand increase. Furthermore, as the value of variable $\mathrm{I}$ in equation 1 increases, the firm tends to ignore e-commerce. Alternatively, as the value of I decreases, the firm tends to adopt e-commerce.

The following equations embody the tendency to employ or ignore e-commerce:

$$
\begin{gathered}
\operatorname{Pr}\left[\Pi^{\circ}>0\right]=\operatorname{Pr}[\mathrm{Xi} * \beta \mathrm{x}+\mathrm{Zi} * \beta \mathrm{z}+\varepsilon \mathrm{i}>0] \\
=\operatorname{Pr}[\varepsilon \mathrm{i}>-(\mathrm{Xi} * \beta \mathrm{x}+\mathrm{Zi} * \beta \mathrm{z})] \\
=\Phi(\mathrm{Xi} * \beta \mathrm{x}+\mathrm{Zi} * \beta \mathrm{z})
\end{gathered}
$$

To estimate the parameters of equation 1 , we use the reduced form of equation 2 , which is equation 4 ,

where

$\mathrm{Xi}$ is a set of variables affecting the net present value of the investment and

$\mathrm{Zi}$ is a set of variables representing the three risk categories.

Then, working on equation 4 , we form the following Maximum Likelihood Equation to determine those drivers that enhance the firm's likelihood to adopt e-commerce and those that push the firm to ignore e-commerce. We now present the following likelihood equation:

$\mathrm{Li}=\mathrm{Ai} * \log (\Phi(\mathrm{Xi} * \beta \mathrm{x}+\mathrm{Zi} * \beta \mathrm{z}))+(1-\mathrm{Ai}) *$

$\left(\log \left(1-\Phi\left(\mathrm{Xi}^{*} \beta \mathrm{X}+\mathrm{Zi} * \beta \mathrm{z}\right)\right)\right.$

where

$\mathrm{Li}$ is the likelihood that the firm will adopt e-commerce;

$\mathrm{Ai}$ is equal to 1 if the specific firm adopts e-commerce, 0 otherwise;

Xi's are the explanatory variables influencing the net present value of the investment;

$\beta \mathrm{x}$ are pseudo-multipliers that drive the firm to adopt e-commerce;

Zi's are the substitute variables of the three risk categories; and

$\beta z$ are the pseudo-multipliers that drive the firm to adopt e-commerce.

Equation 5 now drives the analysis of the data and its subsequent calculations. The objective is now to work towards the estimation of the parameters $\mathrm{Bx}$ and $\mathrm{Bz}$. 


\section{Data Description}

We present here the data used for measuring the in-house competency as well as those of the competition and demand variability.

\subsection{Derivation of In-house Competency Based on the NEBIC Model}

The data supporting the findings of this study are derived from secondary data. The data were derived from a 2011 survey of the in-house competencies of Canadian companies. The in-house competencies were measured using the Net-Enabled Business Innovation Cycle (NEBIC) constructs..,$\underline{34}$ The NEBIC model assesses the in-house competency of the firm to leverage technology based on (a) its capability to choose technology, (b) its capability to match the technology with relevant business applications, and (3) its capability to operate and manage the technology. $\frac{35}{3}$

In Innovation in e-Business Models, $\underline{\underline{5}}$ the in-house competencies of various firms are calculated. From the validated responses coming from 811 firms, the following demographic variables were computed: the number of employees as an indicator of the company size, the previous year's sales, the year the company was founded, and the sector in which the company operates.
Working on the data of ${ }^{5}$ (see Table 1 ), we ascertain that in those who participated in the survey, there seems to be a lower-sector perception of whether the industry is appropriate for e-commerce as shown in Figure 1.

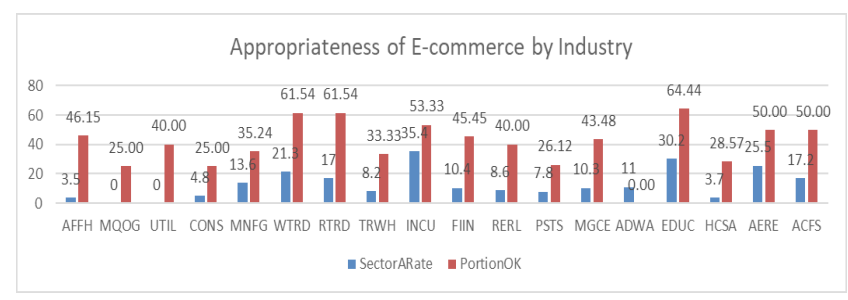

Figure 1. Appropriateness of e-commerce by industry.

Code Legend:

1 AFFH-Agriculture, forestry, fishing, and hunting [11]

2 MQOG-Mining, quarrying, and oil and gas extraction [21]

3 UTIL-Utilities [22]

4 CONS-Construction [23]

5 MNFG-Manufacturing [31-33]

6 WTRD-Wholesale trade [41]

7 RTRD-Retail trade [44-45]

8 TRWH-Transportation and warehousing [48-49]

9 INCU-Information and cultural industries [51]

10 FIIN-Finance and insurance [52]

11 RERL-Real estate and rental and leasing [53]

Table 1. List of variables

\begin{tabular}{|c|c|c|c|}
\hline $\begin{array}{l}\text { S. } \\
\text { No. }\end{array}$ & Symbol & Caption & Meaning \\
\hline 1 & $A_{\mathrm{i}}$ & Adopt_YesNo_i & For firms doing e-commerce, this variable gets the value of 1 ; otherwise it gets 0 . \\
\hline 2 & Competency $y_{\mathrm{i}}$ & NEBIC_value_i & This measures the in-house competency based on NEBIC as computed by Basiouni. \\
\hline 3 & Rivalry & $\begin{array}{l}\text { Firm's_Sector_- } \\
\text { HiLo_Adoption } \\
\text { Rate }\end{array}$ & $\begin{array}{l}\text { For firms having high adoption rate, this variable gets the value of } 1 \text {; otherwise it gets } \\
0 \text {. This measures the number of competitors in the sectors, and this is treated as a } \\
\text { surrogate for adoption rate. }\end{array}$ \\
\hline 4 & $\bigotimes_{\square}$ & Sigma_firm & $\begin{array}{l}\text { This variable measures the sales variability of the firm. This is an indicator of the firm's } \\
\text { sales risk. }\end{array}$ \\
\hline 5 & $\sum_{\mathrm{i}}$ & $\begin{array}{l}\text { Firm's Sector_ } \\
\text { HiLo_Variability }\end{array}$ & For sector having high sales volatility, this variable gets 1 ; otherwise it gets 0 . \\
\hline 6 & $S p x_{\mathrm{i}}$ & Sales_Per_Emp & This variable represents the sales of the firm divided by the staff count. \\
\hline 7 & $N b e_{\mathrm{i}}$ & Number of Emp & This variable is simply the number of staff, a surrogate measure for the size of the firm. \\
\hline 8 & $\mathrm{Yoe}_{\mathrm{i}}$ & $\begin{array}{l}\text { Years_of_- } \\
\text { Existence }\end{array}$ & This variable represents the firm's number of years of its existence. \\
\hline 9 & Inappropriate $_{\mathrm{i}}$ & $\begin{array}{l}\text { Opinion_- } \\
\text { Inappropriate_1 }\end{array}$ & $\begin{array}{l}\text { This variable gets a " } 1 \text { " if the firm's sector is opined to be inappropriate for e-commerce. } \\
\text { The sector's inappropriateness is dependent on the portion of firms (of that sector) who } \\
\text { opined that "going e-commerce is not appropriate for them." }\end{array}$ \\
\hline
\end{tabular}


12 PSTS-Professional, scientific, and technical services [54]

13 MGCE-Management of companies and enterprises [55]

14 ADWA-Admin support, waste management and services [56]

15 EDUC-Educational services [61]

16 HCSA-Health care and social assistance [62]

17 AERE-Arts, entertainment, and recreation [71]

18 ACFS-Accommodation and food services [72]

And when we grouped the industries into seven categories, taking just the first digit of the industry code, for instance, grouping the firms as AERE (arts, entertainment, and recreation) and ACFS (accommodation and food services) and assigning them the number 7 , we have the following:

In Figure 2, it can be seen that the individual firms are optimistic about their actual participation compared to the overall opinion of the industry.

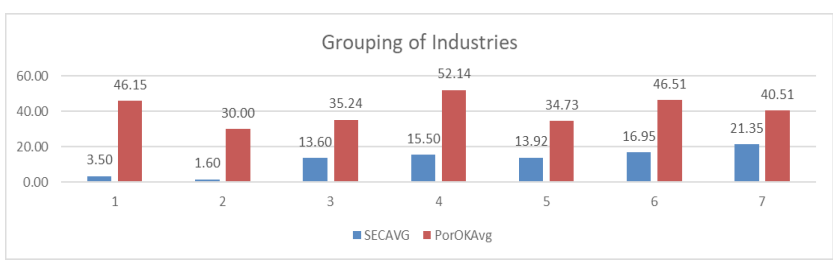

Figure 2. Grouping of industries.

As we can see, those in the blue column bar refer to the sector-specific perception of the appropriateness of using e-commerce. Those in the red column are those who use e-commerce.

\subsection{Derivation of the Industry Rivalry and Firm's Demand Variability Data}

Other secondary data sets for each sector were obtained from Statistics Canada, as described below.

Data Set B1. Monthly time series of the Gross Domestic Value.

Data Set B2. Percentage of businesses transacting on the internet and the issues of having sales transaction online for each sector.

Using those available data sets B1 and B2, we compute the following variables:

Considering equation 5, $\mathrm{X}_{\mathrm{i}}$ includes Sales ${ }_{\mathrm{i}}$, Size $_{\mathrm{i}}$, $\operatorname{Exp}_{\mathrm{i}}$ and Inappropriate $\mathrm{i}_{\mathrm{i}}$. On the other hand, $\mathrm{Zi}$ includes In-house Competency $y_{i}, \sigma_{i}, \sum i$ and Rivalry ${ }_{\mathrm{i}}$.
A good estimate of $\sigma \mathrm{i}$ is obtained by collecting the time series data for each firm included in the survey. As this is difficult to obtain, the riskiness of the firm's sales is calculated by using the sales' cross-sectional values as an estimate of the distribution function. The distribution function becomes the basis of the $\sigma \mathrm{i} .32$

First, Sales $_{\mathrm{i}}$ is regressed on a set of explanatory sets of variables. That is,

$$
\text { Sales }_{\mathrm{i}}=\mathrm{X}_{\mathrm{i}} * \mathrm{~B}+\mathrm{v}
$$

Where:

Sales $_{i}=$ level of the firm revenue

$\mathrm{Xi}=$ set of the explanatory variable (This includes In-house Competency, Size, Yoe -Years of Existence, and sector dummies.)

The error estimates are consistent as evidenced by the consistency of the OLS (Ordinary Least Squares) estimates of B.

\section{Discussion of Results}

Based on the details presented in Table 2, it can be seen that there is a very high correlation between the sector variability and the firms who adopted online selling strategy. It is noted that in this computation, the variable rivalry is a surrogate variable for adoption. Furthermore, no correlation is established between those who ignored e-commerce to sector variability.

Table 2. Sector-level variables correlation matrix

\begin{tabular}{|l|l|l|l|}
\hline & $\begin{array}{l}\text { Rivalry } \\
\text { (adopted) }\end{array}$ & $\begin{array}{l}\text { Inappropriate } \\
\text { (ignored) }\end{array}$ & $\begin{array}{l}\text { Sigma } \\
\text { (sector) }\end{array}$ \\
\hline $\begin{array}{l}\text { Rivalry } \\
\text { (adopted) }\end{array}$ & 1.000 & 1.000 \\
\cline { 1 - 2 } $\begin{array}{l}\text { Inappropriate } \\
\text { (ignored) }\end{array}$ & 0.068 & 1.000 & \\
\cline { 1 - 2 } Sigma (sector) & 0.711 & 0.227 & \\
\hline
\end{tabular}

There are 20 sectors.

Table 3 shows a comparison of those who adopted e-commerce with those who ignored it; this comparison asserts that the difference between in-house competency, sales volatility, and years of existence is significant. The data suggest that adopters are more capable, have experience working in rough sales environment, and are relatively younger. The number of employees and sales per employee do not seem to be relevant. 
Table 4. Probit model maximum likelihood estimation (MLE) results

\begin{tabular}{|l|l|l|l|}
\hline Coefficient & Value & z-Statistic & Prob. \\
\hline Constant & -1.3151 & -4.6515 & 0.0000 \\
\hline$\beta_{\text {Competency }}$ & 0.0843 & 3.6113 & 0.0003 \\
\hline$\beta_{\text {Rivalry }}$ & 0.3893 & 1.9189 & 0.0550 \\
\hline$\beta_{\sigma 2}$ & 0.2990 & 2.3314 & 0.0197 \\
\hline$\beta_{\Sigma 2}$ & 0.4960 & 2.5212 & 0.0117 \\
\hline$\beta_{\text {Yoe }}$ & -0.0118 & -2.3238 & 0.0201 \\
\hline$\beta_{\text {Sales }}$ & -0.0004 & -0.0062 & 0.9950 \\
\hline$\beta_{\text {Inappropriate }}$ & 0.4376 & 2.3148 & 0.0206 \\
\hline
\end{tabular}

Table 5. Supporting data for the MLE calculation

\begin{tabular}{|l|l|}
\hline Log-likelihood & 380.280 \\
\hline Standard deviation, dependent variable & 0.480 \\
\hline McFadden $R^{2}$ & 0.055 \\
\hline Likelihood ratio statistic & 44.460 \\
\hline Probability (LR statistic) & 0.000 \\
\hline Count of observations for A =0 & 396 \\
\hline Count of observations for A = 1 & 221 \\
\hline Overall observations (missing values removed) & 617 \\
\hline
\end{tabular}

Given the results presented in Table 4 and 5, this discourse claims that the enterprise is likely to transact through the Internet if it exhibits the following characteristics: high competency of technology $\left(\beta_{\text {Competency }}>0\right)$, firm situated in a sector where demand is variable $\left(\beta_{\text {Unsuitable }}>0\right)$, and high demand volatility $\left(\beta_{\sigma 2}>0\right)$.

The computation has sustained the first hypothesis $\left(\mathrm{H}_{1}\right)$ that firms with high-level in-house competency are more likely to transact online. Furthermore, reasserting the result inspired by the NEBIC model, we found that firms who are able to utilize the potential of information technology are also capable of pairing it with appropriate economic decisions and skilfully manage projects by transacting via e-commerce, even in an uncertain environment.

The second hypothesis $\left(\mathrm{H}_{2}\right)$ is supported as well. The second hypothesis claims that a vibrant and highcompetition environment is associated with more firms adopting e-commerce. In this situation, the decision to adopt online selling becomes a strategic move, and the option to wait for further developments loses its appeal.

However, the third hypothesis $\left(\mathrm{H}_{3}\right)$ is not supported. The third hypothesis claims that high sales uncertainty induces a firm to hold out and wait for a better time before making a move towards e-commerce. The computation does not support this. Considering that $\beta_{\sigma 2}$ and $\beta_{\Sigma 2}$ are both positive and significant, this implies that high sales uncertainty encourages a firm to adopt online selling. Furthermore, this discourse implies that enterprises adopt e-commerce as a safeguard when the economy turns bad.

\section{Conclusion}

By using the real-options approach as discussed, this study concludes that firms' resolve to move on to e-commerce is influenced heavily by various factors: the level of in-house competency, risk of competition, and risk of market demand volatility and unpredictability. Finally, this study suggested three flexibility-attaining activities: (1) intensive in-house training on e-commerce technology, (2) promotion of e-commerce among customers, and (3) encouraging other industry members to adopt e-commerce. Furthermore, we conclude that the following factors lead towards the adoption of e-commerce: (1) high in-house competency to manage information technology, (2) strong rivalry within the industry, and (3) high variability in sales performance.

Finally, as for flexibility-attaining activities (sometimes referred to as agility), it is recommended that firms engage in (1) in-house training and development on the latest e-commerce technology, (2) promote e-commerce as the preferred mode of buying among the clientele, and (3) encourage other industry members to move on to e-commerce from traditional ways of doing business.

\section{Acknowledgement}

The authors of the study would like to acknowledge the support brought by King Fahd University of Petroleum \& Minerals (KFUPM), Dhahran, Saudi Arabia, and Yanbu University College, Royal Commission for Yanbu Project, Saudi Arabia.

\section{References}

1. Information and communications technologies and electronic commerce in Canadian industry. [cited 1999]. https:// www150.statcan.gc.ca/n1/en/catalogue/88F0006X2000004.

2. Alotaibi S, Osmani S, Pricec ADF. A framework for improving project performance of standard design models in Saudi Arabia. J Eng Proj Manag. 2013;3(2):85-98. 
3. Basiouni A. A multi-group analysis of innovation in online business models. Pertanika J Soc Sci Hum (JSSH). 2018;26(T):51-62.

4. Benaroch M. Managing information technology investment risk: a real options perspective. J Manag Inf Syst. 2002;19(2):43-84.

5. Innovation in e-business models: a net-enabled business innovation cycle (NEBIC) theory perspective with empirical evidence. [cited 2011]. https://www.semanticscholar. org/paper/Innovation-in-e-business-models\%3A-A-netenabled-with-Basiouni-McNaughton/493170442e286ce0a 750a43a333fc2d7a165e867.

6. Alojairi A, Akhtar N, Hafizi A, Basiouni A. Assessing Canadian business IT capabilities for online selling adoption: a net-enabled business innovation cycle (NEBIC) perspective. Sustainability. 2019;11(13):3662.

7. Senarathna I, Warren M, Yeoh W, Salzman S. The influence of organization culture on e-commerce adoption. Ind Manag Data Syst. 2014;114(7):1007-21.

8. Lee VH, Foo ATL, Leong LY, Ooi KB. Can competitive advantage be achieved through knowledge management? A case study on SMEs. Expert Syst Appl. 2016;65:136-151.

9. Loane S, Bell J, Deans KR. Internet adoption by rapidly internationalizing SMEs: a further challenge to staged e-adoption models. Int J Entrepr Small Bus. 2007;4(3):277-90.

10. The internet and business performance. [cited 2000]. https://www.oecd-ilibrary.org/science-and-technology/ the-internet-and-business-performance_233751540382.

11. Loane S, McNaughton RB, Bell J. The internationalization of internet-enabled entrepreneurial firms: evidence from Europe and North America. Can J Admin Sci/Revue Canadienne des Sciences de l'Administration. 2004;21(1):79-96.

12. Examining barriers to business e-commerce. [cited 2007]. https://www150.statcan.gc.ca/n1/pub/88-003$\mathrm{x} / 2007001 / 4064503$-eng.htm.

13. Ansari Z. Socio-cultural influences on online shopping behaviour. J Bus Retail Manag Res. 2018;13(2):255-63.

14. Ansari Z. Measuring online consumer behavior: scale development \& validation. J Bus Retail Manag Res. 2019;13(3):222-34.

15. Efrim Boritz J, No WG. Security in xml-based financial reporting services on the internet. J Account Public Policy. 2005;24(1):11-35.

16. Boynton AC, Zmud RW, Jacobs GC. The influence of IT management practice on IT use in large organizations. MIS Q. 1994;18(3):299-318.

17. Yap C, Soh C, Raman K. Information systems success factors in small business. Omega. 1992;20(5):597-609.

18. Awa HO, Ojiabo OU, Emecheta BC. Integrating TAM, TPB and TOE frameworks and expanding their characteristic constructs for e-commerce adoption by SMEs. J Sci Technol Policy Manag. 2015;6(1):76-94.
19. Oppong-Tawiah D, Yolande EC. The influence of IT and knowledge capabilities on the survival of university IT startups. Int J Technoentrepr. 2016;3(2):150-72.

20. Adner R, Levinthal DA. What is not a real option: considering boundaries for the application of real options to business strategy. Acad Manag Rev. 2004;29(1):74-85.

21. Investment under uncertainty. [cited 1994]. https:// msuweb.montclair.edu/ lebelp/DixitPindyck1994.pdf.

22. Real options and investment under uncertainty: classical readings and recent contributions. [cited 2004]. https://mitpress.mit.edu/books/ real-options-and-investment-under-uncertainty.

23. Trigeorgis L, Reuer JJ. Real options theory in strategic management. Strat Manag J. 2017;38(1):42-63.

24. Mintah K, Higgins D, Callanan J, Wakefield R. Staging option application to residential development: real options approach. Int J Hous Mark Anal. 2018;11(1):101-16.

25. de Almeida GL, Dias MAG, Brandão L, Eduardo T, Samanez CPM. A real options model with games applied to the Rio de Janeiro residential real estate market. Braz J Bus Manag. 2019;21(1):118-35.

26. Madhani PM. Effective salesforce management practices: a real option approach. IUP J Bus Strat. 2018;15(1):7-24.

27. Jing Li. Real options theory and international strategy: a critical review. Adv Strat Manag. 2007;24:67-101.

28. Sandal LK, Stein IS, Ayoe H. Irreversible investments revisited. Mar Resour Econ. 2007;22:255-66.

29. Irreversible investment and uncertainty: an empirical study of rice mills in the Mekong river delta, Vietnam. [cited 2003 Jan]. https://www.researchgate.net/ publication/4787196_Irreversible_investment_and_ uncertainty_an_empirical_study_of_rice_mills_in_the_ Mekong_river_delta_Vietnam.

30. Ming Z, Ping Z, Shunkun Y, Ge Z. Decision-making model of generation technology under uncertainty based on real option theory. Energy Convers Manag. 2016;110:59-66.

31. Tong WT, Reuer JJ. Real options in strategic management. Adv Strat Manag. 2007;24:3-28.

32. Koundouri P, Nauges C, Tzouvelekas V. Technology adoption under production uncertainty: theory and application to irrigation technology. Am J Agric Econ. 2006;88(3):657-70.

33. Bulan LT, Mayer C, Somerville CT. Irreversible investment, real options, and competition: evidence from real estate development. J Urban Econ. 2009;65:237-51.

34. Wheeler BC. NEBIC: a dynamic capabilities theory for assessing net-enablement. Inf Syst Res. 2002;13(2):125-46.

35. Ehrenhard M, Wijnhoven F, van den Broek T, Stagno MZ. Unlocking how start-ups create business value with mobile applications: Development of an app-enabled business innovation cycle. Technol Forecast Soc Change. 2017;115:26-36. 